\title{
Strategi Penataan Kawasan Pantai Klayar Pacitan Sebagai Destinasi Pariwisata Berkelanjutan Dengan Prinsip Arsitektur Ekologis
}

\author{
Sri Yuliani1, Wiwik Setyaningsih ${ }^{2}$, Yosafat Winarto ${ }^{3}$ \\ 1,2,3Architecture Department, Universitas Sebelas Maret, Indonesia \\ sriyuliani71@staff.uns.ac.ic
}

\begin{abstract}
ABSTRAK
Potensi pariwisata Pantai Klayar di Kabupaten Pacitan semakin meningkat seiring dengan pengembangan program kepariwisataan di Indonesia yang mencakup pengembangan kawasan pantai sebagai destinasi pariwisata alam. Pengembangan kawasan pantai untuk pengembangan potensi pariwisata lokal berbasis alam memerlukan strategi penanganan yang memperhatikan beberapa dasar pertimbangan yang selaras dengan lingkungan agar kendala rawan bencana dapat diminimalkan, diantaranya meliputi aspek konservasi alam. Strategi pengembangan pantai Klayar dapat dilakukan melalui penerapan prinsip Arsitektur Ekologis. Lokasi penelitian di kawasan Pantai Klayar yang merupakan salah satu dari 9 (sembilan) prioritas destinasi pariwisata Kabupaten Pacitan. Penelitian ini bertujuan untuk menemukan strategi penataan kawasan dengan penerapan prinsip arsitektur ekologis, yakni mengoptimalkan nilai potensi daerah dan tetap mempertimbangkan kelestarian alam. Metode penelitian menggunakan deskriptif kualitatif dengan melakukan survei melalui pengamatan, wawancara dan membandingkan teori dengan regulasi yang relevan. Hasil penelitian merupakan strategi penataan kawasan untuk mengembangkan potensi Pantai Klayar melalui penataan area pariwisata sesuai dengan unsur lokalitas dan budaya setempat serta konservasi alam yang terpadu sehingga menjadi destinasi pariwisata berkelanjutan.
\end{abstract}

Kata kunci: strategi penataan kawasan, pantai Klayar, pariwisata berkelanjutan, arsitektur ekologis

\section{ABSTRACT}

The tourism potential of Klayar Beach in Pacitan Regency is increasing along with the development of tourism programs in Indonesia which include the development of coastal areas as natural tourism destinations. The development of the coastal area for the development of the potential of local tourism based on nature requires a handling strategy that takes into account a number of considerations that are in harmony with the environment so that disaster-prone constraints can be minimized, including covering aspects of nature conservation. The strategy for developing Klayar Beach can be done through the application of the principles of Ecological Architecture. The research location in the Klayar Beach area is one of the 9 (nine) priority tourism destinations in the Regency of Pacitan. This study aims to find a regional structuring strategy with the application of the principles of ecological architecture, namely optimizing the value of regional potential and still considering the sustainability of nature. The research uses descriptive qualitative method by conducting surveys through observation, interviews and comparing theories with relevant regulations. The results of the study are regional structuring strategies to develop the potential of Klayar Beach through structuring tourism areas in accordance with local elements and local culture as well as integrated nature conservation so that it becomes a sustainable tourism destination.

Keywords: regional structuring strategy, Klayar Beach, sustainable tourism, ecological architecture 


\section{Pendahuluan}

Kabupaten Pacitan merupakan suatu kabupaten yang sebagian wilayahnya berada di pesisir pantai Pulau Jawa, terletak dekat perbatasan Jawa Tengah dan Jawa Timur seperti ditunjukkan pada Gambar 1. Kabupaten ini mempunyai potensi pariwisata alam yang membentang dari pesisir timur hingga barat bahkan ada juga beberapa goa dan obyek wisata alam lain yang menarik. Bupati Pacitan melalui peraturan daerah menyusun strategi untuk mengupayakan pengelolaan sumber alam potensi pariwisata secara menyeluruh, mulai dari pembangunan infrastruktur, tata cara pengelolaan hingga pemasaran pariwisata (Bupati Pacitan, 2013) (Riparkab, 2016).

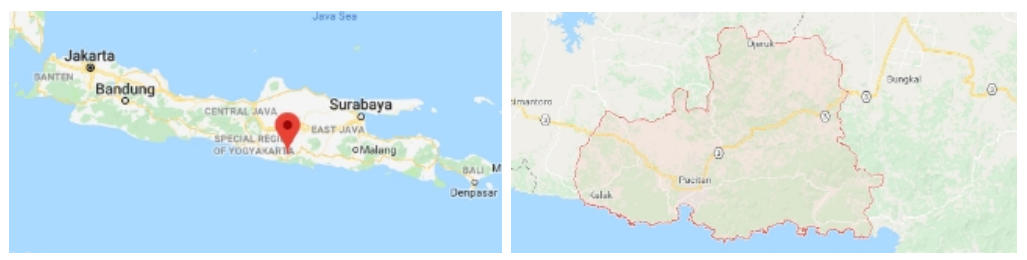

Gambar 1. Lokasi Kabupaten Pacitan

Kunjungan pariwisatawan dari tahun ke tahun, pada beberapa lokasi destinasi pariwisata Kabupaten Pacitan secara menyeluruh semakin meningkat, ditunjukkan pada Gambar 2. Peningkatan kunjungan terasa melonjak sejak tahun 2014 dan 2015. Pada tahun 2016 dan 2017 jumlah kunjungan tetap naik meskipun tingkat perbedaannya cukup tipis. Data kunjungan pariwisatawan dikalkulasi dari jumlah pariwisatawan dalam negeri dan luar negeri. Jumlah pariwisatawan luar negeri juga meningkat, walaupun masih dalam angka yang relatif kecil, yang terbanyak sekitar 123 orang di bulan September dengan lokasi Pantai Banyu Tibo. Sedangkan untuk Pantai Watu Karung berkisar 104 orang dan Pantai Klayar masih belum ada kunjungan pariwisatawan dari luar negeri. Berdasarkan pertimbangan tersebut, pengembangan pariwisata alam pantai di Pacitan memerlukan dukungan terutama untuk menyusun strategi penataan kawasan Pantai Klayar sebagai pantai yang berpotensi dengan keindahan alam yang memiliki ciri khusus, agar menjadi destinasi pariwisata yang diminati baik dari dalam negeri maupun luar negeri.

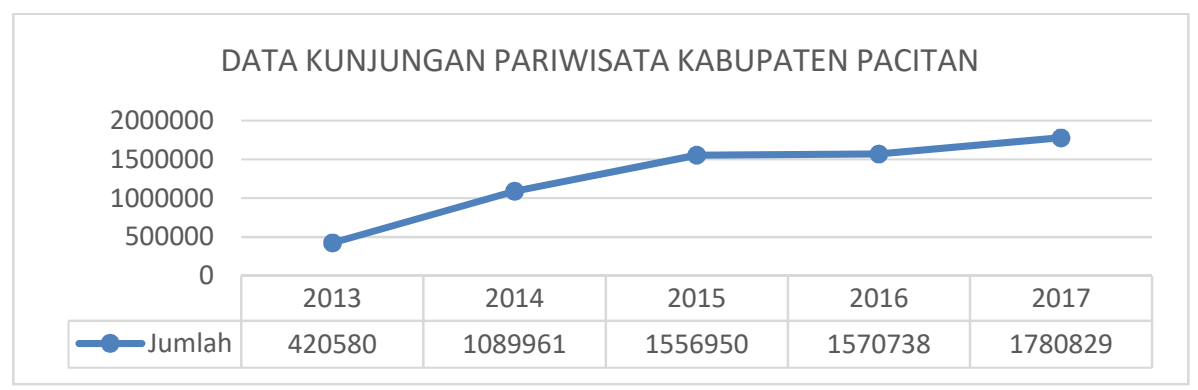

Gambar 2. Statistik Kunjungan Tahun 2013 hingga 2017

Sumber: (Dinas Pariwisata, 2017)

Di antara beberapa obyek pariwisata yang berpotensi di Kabupaten Pacitan, Pantai Klayar memiliki prospek yang semakin meningkat, dapat dilihat dari data kunjungan secara menyeluruh berdasarkan lokasi seperti pada Gambar 3. Pantai Klayar merupakan destinasi pariwisata peringkat kedua setelah Pantai Teleng Ria, dari data jumlah kunjungan pada tahun 2017. 


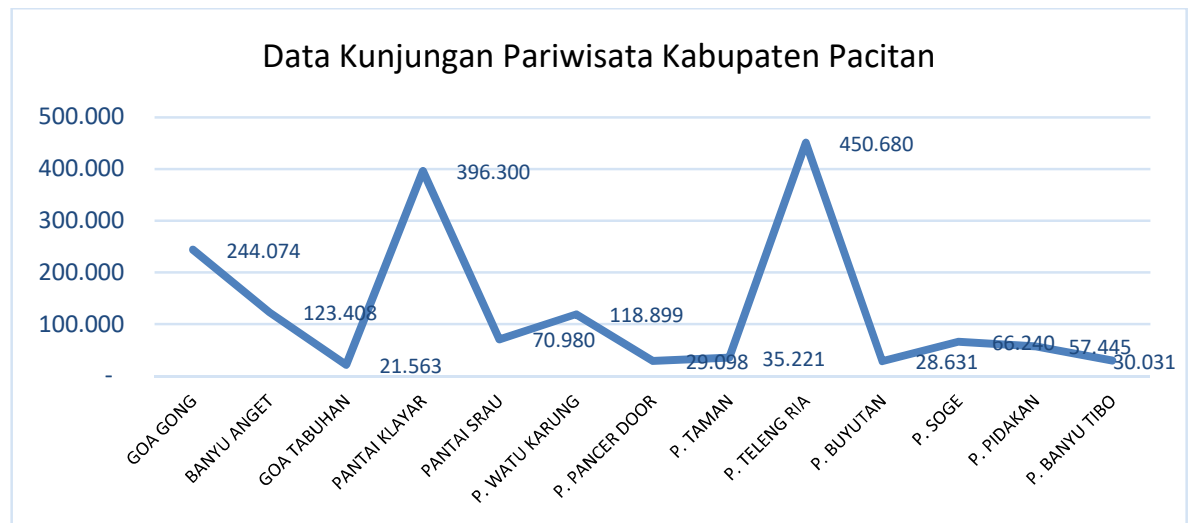

Gambar 3. Statistik Kunjungan Pariwisata Kabupaten Pacitan pada Beberapa Lokasi di Tahun 2017

Sumber: (Dinas Pariwisata, 2017)

Kondisi minat pariwisata Pantai Klayar diprediksikan akan semakin meningkat sebagai alternatif pengganti Pantai Teleng Ria. Dimana pada akhir tahun 2017, Pantai Teleng Ria yang menjadi favorit pariwisata mengalami kerusakan yang parah akibat banjir besar di Kabupaten Pacitan. Banyak fisilitas pariwisata seperti kolam renang serta fasilitas penunjang lain di kawasan Pantai Teleng Ria rusak dan bahkan ada yang tidak berfungsi lagi. Beberapa kerusakan meliputi akses jalan lingkar pantai yang terpotong karena tanah longsor, kotoran dan sampah sisa-sisa banjir yang masih belum dibersihkan, gasebo di pinggir pantai yang rusak, area makan dan kios souvenir yang belum pulih, seperti pada Gambar 4.
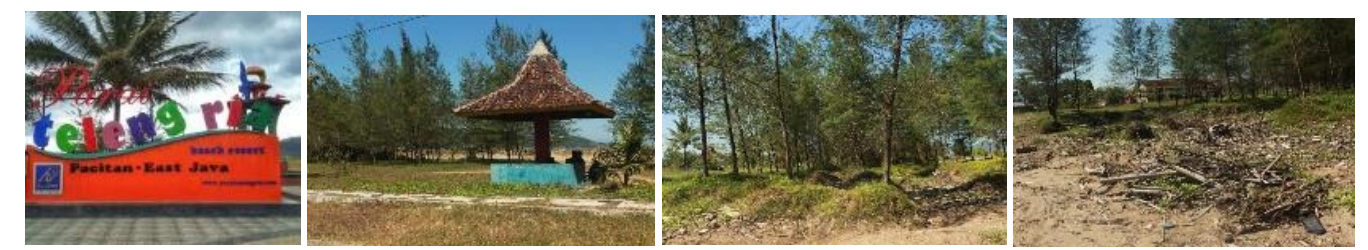

Gambar 4. Kondisi Pantai Teleng Ria akibat bencana banjir di Kabupaten Pacitan.

Upaya meningkatkan minat pariwisata Kabupaten Pacitan tetap tidak surut walaupun kendala rawan bencana yang terjadi. Beberapa alternatif destinasi pariwisata mulai dikembangkan, salah satunya adalah Pantai Klayar. Pantai Klayar merupakan pantai yang memiliki daya tarik dengan bentangan pasir putih yang bersih, air laut yang berwarna biru tosca, batu karang putih kecoklatan yang mempesona, dan air mancur alami di sela gugusan karang. Ciri khas yang menonjol dari pantai ini adalah bentuk bukit dari batuan karang karst yang hampir memiliki tampilan seperti Tanah Lot di Bali. Sumber informasi kepariwisataan yang diperoleh, secara historis, menyebutkan bahwa istilah sebutan klayar berasal dari asal kata percakapan lokal yaitu klayar-kluyur yang berarti berjalan-jalan. Sesuai dengan namanya, pantai Klayar menjadi tempat menarik bagi warga sekitar untuk menikmati keindahan alam, bersantai bersama keluarga atau kolega.

Pantai Klayar akan terlihat tambah menawan ketika cuaca sedang cerah, maka pada kondisi tersebut, akan ada perpaduan warna biru laut yang menawan, sementara pada tepian terdapat deretan perbukitan karang berwarna coklat muda bergradasi hingga coklat tua, berbaris rapi di tepian dengan tinggi rendah yang dinamis sehingga membentuk pemandangan yang menarik. Deretan karang tersebut berpadu dengan bentangan pasir putih yang lapang dan mempesona, sehingga tersedia ruang yang luas untuk dapat bermain-main di pinggiran pantai atau sekedar jalan berkeliling untuk mencari bendabenda laut yang terbawa arus ombak. Layaknya sebuah kawasan pantai, vegetasi berupa 
pohon-pohon kelapa dan pandan laut tumbuh liar di sekitarnya. Ketika hari menjelang senja merupakan waktu yang tepat untuk menikmati keindahan Pantai Klayar, akan tampak sinar matahari mulai tenggelam dengan warna lembayung dengan spektrum jingga kemerahan terlihat di garis batas barat pantai. Waktu pemandangan sunset yang indah ini perlu diwadahi dalam ruang yang mendukung suasana. Di balik tebing-tebing karst yang merupakan struktur bumi hasil pelarutan batuan gamping, granit, atau batuan pasir lainnya, menjulang tinggi puluhan meter menyerupai Sphinx, terdapat air mancur alam yang mempunyai daya tarik tersendiri. Ketika ombak datang dengan cukup deras, sebagian airnya masuk ke bawah batu dan menyembur ke atas seolah sebuah air mancur raksasa yang bisa mencapai ketinggian hingga 10 meter. Air mancur ini juga disertai dengan suara mirip siulan sehingga sering disebut sebagai Seruling Laut.. Keunikan inilah yang menjadikan pantai Klayar sebagai salah satu pantai yang mempesona secara alami di Pacitan seperti disajikan pada Gambar 5.

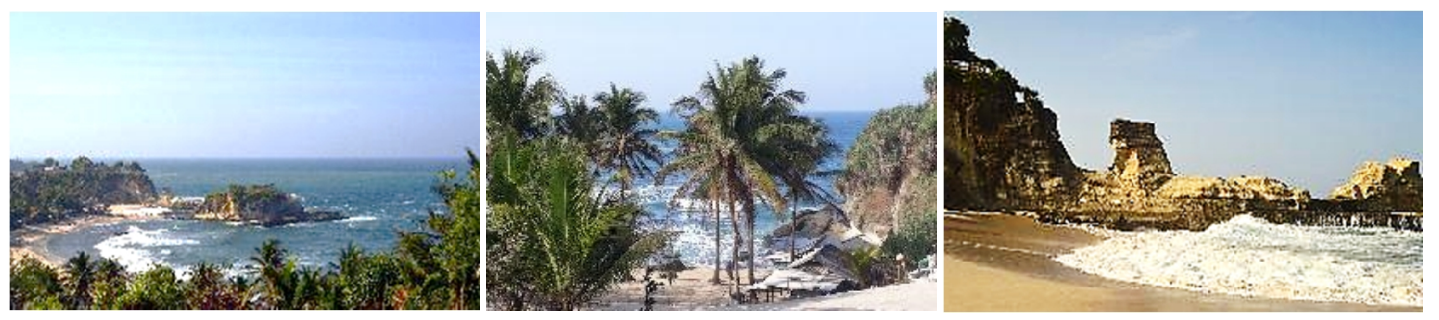

Gambar 5. Pesona Pantai Klayar

Selain keindahan alam, kawasan Pantai Klayar memiliki tradisi yang masih mengandalkan ketrampilan masyarakat dalam berinteraksi, diantaranya masyarakat setempat dapat memanjat pohon kelapa yang tinggi tanpa alat bantu, untuk mengambil air deresan (bahan baku untuk pembuatan gula jawa) atau hanya untuk disuguhkan langsung kepada. Potensi pantai Klayar yang berpeluang dikembangkan dapat mengangkat potensi pariwisata agar meningkatkan ekonomi desa pariwisata. Daya tarik alam di sekitar pantai Klayar dapat dikemas dalam kegiatan yang saling penunjang untuk mendukung Pantai Klayar sebagai destinasi pariwisata diantaranya resort dengan pendekatan fenomenologi arsitektur (Pramudhita, Pitana, \& Yuliani, 2016).

Sejalan dengan tiga prioritas unggulan yang menjadi target Kementerian Pariwisata (Kemenpar) untuk mengembangkan industri pariwisata di Indonesia, disebutkan dalam pertemuan yang diagendakan pada Rapat Koordinasi Nasional (Rakornas) Kepariwisataan I 2017, mengamanatkan pengembangan pariwisata mencakup promosi melalui dunia maya yakni menyebarluaskan informasi pariwisata secara online di internet, pembangunan desa wisata baik fisik maupun non fisik, dan pengembangan jalur transportasi udara yang dapat memberikan layanan kemudahan mengakses daerah tujuan wisata di Indonesia. Oleh karenanya, pembangunan beberapa desa wisata di Kabupaten Pacitan perlu mendapat prioritas sebagai upaya membangun desa wisata menjadi desa wisata berkualitas sesuai dengan amanah sapta pesona yang aman, tertib, bersih, indah, sejuk, ramah tamah, dan kenangan. Prioritas yang utama adalah strategi dalam pengelolaan kawasan pantai sebagai destinasi wisata alam yang aman, nyaman dan menarik untuk dikunjungi. Pengelolaan Pantai Klayar mempertimbangkan potensi fisik dan non fisik daerah setempat sehingga akan mempunyai kesigapan terhadap kendala yang ada, namun tetap berkembang dengan segala potensi yang dimiliki.

Penelitian ini bertujuan menemukan rumusan strategi untuk pengembangan pantai Klayar sebagai destinasi pariwisata yang tanggap bencana dengan berbasis penerapan konsep arsitektur ekologis. Strategi pengembangan meliputi model pengelolaan secara terpadu dengan melibatkan pemangku kepentingan dan model perancangan yang berciri 
khusus untuk menguatkan potensi alam terutama di sekitar pantai dan budaya masyarakat desa Sendang yang merupakan lokasi pantai Klayar.

\section{Kajian Pustaka}

Peraturan Bupati Pacitan yang tertuang dalam Peraturan Daerah Kabupaten Pacitan Nomor 7 Tahun 2013 Tentang Penyelenggaraan Keparipariwisataan, pada pasal ke-4 menyebutkan bahwa keparipariwisataan bertujuan untuk: a. meningkatkan pertumbuhan ekonomi; b. meningkatkan kesejahteraan rakyat; c. menghapus kemiskinan; d. mengatasi pengangguran; e. melestarikan alam, lingkungan, dan sumber daya; $f$. memajukan kebudayaan; g. mengangkat citra bangsa; h. memupuk rasa cinta tanah air; i. memperkukuh jati diri dan kesatuan bangsa; dan j. mempererat persahabatan antar bangsa (Bupati Pacitan, 2013). Secara detail dalam Rencana Induk Pembangunan Kepariwisataan Kabupaten Pacitan Tahun 2016-2025 (Riparkab, 2016) diuraikan bahwa prinsip pembangunan kepariwisataan yang berkelanjutan diantaranya pengembangan kepariwisataan kabupaten yang berwawasan lingkungan melalui sinergi pengelolaan lingkungan secara terpadu dan berkesinambungan. Riparda menetapkan bahwa Pantai Klayar sebagai salah satu Destinasi Pariwisata Kabupaten (DPK) A Wisata Geopark. Dengan demikian keunikan visual geopark menjadi unggulan kawasan Pantai Klayar sehingga perlu untuk didukung dengan program-progran kelestarian dan konservasi alam.

Selaras dengan tujuan melestarikan alam, lingkungan dan sumber daya alam, upaya pengembangan pariwisata dapat dikelola dengan model interaksi solid antar pemangku kepentingan. Sistem kepariwisataan menyangkut faktor permintaan (demand) dan faktor penawaran (supply). Keseimbangan antara faktor permintaan dan penawaran (demand and supply match) merupakan tujuan dari pembangunan pada umumnya. Dalam kaitannya dengan Desa Wisata Hijau, keseimbangan ini dimaksudkan bertemunya permintaan dengan penawaran dalam konteks pelestarian, kepuasan wisatawan, kepuasan komunitas, dan kepuasan lingkungan (Victoria, et al., 2012). Model hubungan memusat pada sektor kepariwisataan seperti pada Gambar 6 dapat menjadikan inovasi dalam menyusun strategi menuju pengembangan desa wisata hijau yang berkelanjutan.

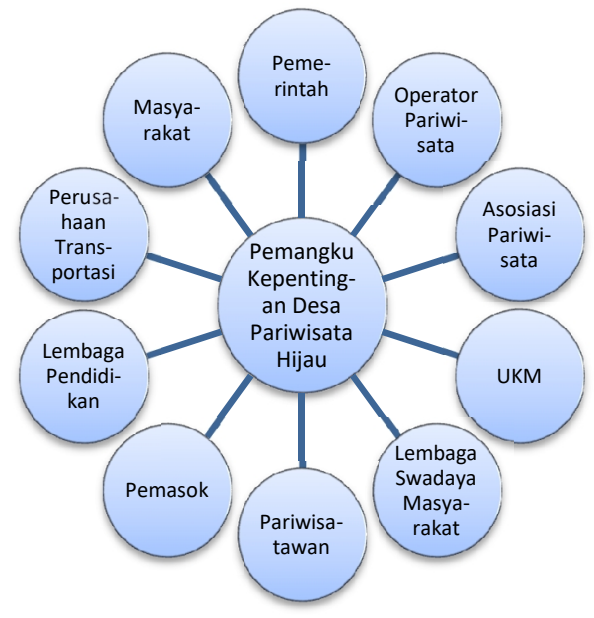

Gambar 6. Model Pengembangan Pariwisata Sumber: (Victoria, et al., 2012)

Peraturan Bupati Pacitan, melalui Rencana Induk Pembangunan Kepariwisataan Kabupaten Pacitan Tahun 2016-2025 (Riparkab, 2016), menjaring masyarakat untuk terlibat berperan dalam pembangunan pariwisata dengan pemberdayaan masyarakat baik peningkatan kapasitas hingga penguatan kesadaran pariwisata. Selain itu juga pengembangan investasi dan pemasaran. Tujuan pembangunaan sektor pariwisata tidak 
semata untuk peningkatan ekonomi kabupaten, namun juga peningkatan kualitas hidup masyarakat dan lingkungan alam yang berada pada wilayah Kabupaten Pacitan di pesisir pulau Jawa yang tentunya rawan dengan bencana.

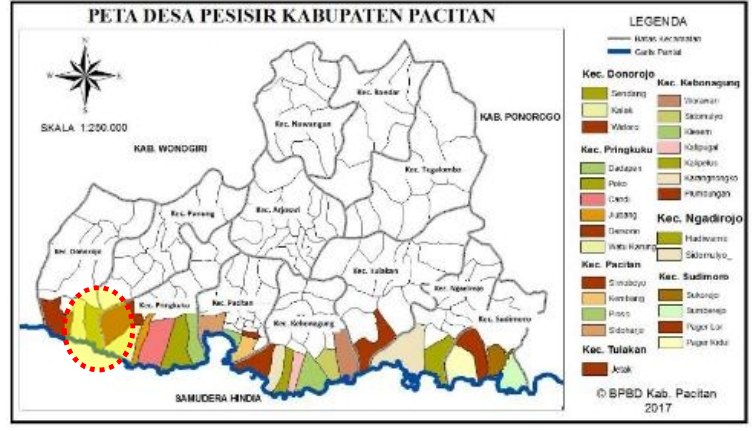

Keterangan:

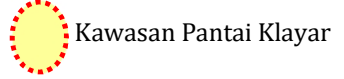

Gambar 7. Pemetaan daerah pesisir yang rawan bencana. Sumber: (BPBD Pacitan, 2017)

Penataan kawasan pariwisata memerlukan pertimbangan faktor mitigasi bencana agar penyelenggaran kegiatan pariwisata dapat dinikmati dengan aman, nyaman dan menjadi kenangan sesuai Sapta Pesona Pariwisata Indonesia. Berdasarkan pemetaan rawan bencana oleh Badan Penanggulangan Bencana Daerah Kabupaten Pacitan, Pantai Klayar berada di area pesisir yang menghadap gelombang ombak besar dari Samodera Hindia seperti pada Gambar 7, sehingga kawasan ini merupakan titik rawan gempa dan tsunami. Hal ini menjadi pertimbangan dalam menyusun strategi penataan kawasan dengan menjadikan area depan bibir pantai sebagai area non pariwisata namun sebagai area konservasi dan mitigasi bencana.

Pembangunan dengan prinsip arsitektur ekologis merupakan konsep membangun yang mempertimbangkan keselarasan antara manusia, bangunan dan lingkungan (Frick \& Mulyani, 2006). Ketiganya menjadi faktor yang mempengaruhi penentuan rancangan agar wadah yang disediakan menjadi tempat yang memberikan keuntungan yang seimbang dan ketiganya dapat berkelanjutan. Unsur-unsur yang perlu diperhatikan pada strategi penataan kawasan adalah kelestarian dan konservasi lingkungan; kesehatan dan kenyamanan wadah kegiatan; serta efisiensi, keselamatan dan durabilitas bangunan. Dalam implementasi prinsip arsitektur ekologis pada penataan destinasi pariwisata, tentunya tetap mempertimbangkan keharmonisan kebutuhan manusia, desain bangunan pariwisata dan kelestarian lingkungan alam.

\section{Metode}

Metode penelitian menggunakan metode deskriptif kualitatif dengan melakukan kajian dan analisis melalui obyek empirik di Pantai Klayar dan potensi lingkungan serta budaya Kabupaten Pacitan; analisis teoritikal tentang regulasi lokal hingga nasional dan teori pengelolaan desa pariwisata serta prinsip arsitektur ekologis. Penelitian tentang Pantai Klayar ini merupakan penelitian deskriptif kualitatif jenis survei (Nazir, 2014), yakni melalui pengamatan secara detil di lapangan untuk mendapatkan data yang sesungguhnya dari obyek di lapangan, mendapatkan faktor penentu yang ada dan mencari keterangan secara faktual. Penelitian ini juga membandingkan antara fenomena dan regulasi maupun teori terkait untuk menemukan tujuan penelitian.

Tahapan penelitian diawali dengan pengamatan dan wawancara untuk mengidentifikasi potensi dan kendala Pantai Klayar. Perolehan data meliputi data kunjungan, fasilitas pariwisata yang tersedia, aksesiblitas lokasi dan kondisi eksisting obyek diverifikasi untuk mengidentifikasi permasalahan terkait potensi, kendala dan prospek destinasi pariwisata. Data yang diperoleh tahap pertama, berupa data fisik yang mengidentifikasi lokasi dan kriteria alam di Pantai Klayar yang telah ada dan rencana pemerintah daerah setempat. Tahap berikutnva, mengadakan wawancara dengan pelaku 
pariwisata untuk mengidentifikasi partisipasi pelaku pariwista. Selanjutnya, mengumpulkan data non fisik sebagai informasi terkait dengan regulasi yakni peraturan bupati, undang-undang pariwisata dan teori yang relevan untuk membangun strategi penataan kawasan.

\section{Hasil dan Pembahasan}

Pantai Klayar merupakan salah satu pantai di Pacitan yang berada di pesisir Pulau Jawa, terletak di Desa Sendang, Kecamatan Donorojo, Kabupaten Pacitan, Jawa Timur. Pantai Klayar dapat dicapai dengan jarak kira-kira 35 kilometer hingga 40 kilometer menuju arah barat dari Kota Pacitan. Apabila menelusuri dengan menggunakan mobil, dapat ditempuh dalam waktu sekitar 90 menit dari pusat Kota Pacitan. Karakteristik pantai Klayar yakni memiliki ombak yang sangat besar dan bergulung hingga mencapai ketinggian 2 meter. Ombak besar ini sering kali membawa bencana bagi pariwisatawan yang kurang hati-hati dan tidak memperhatikan keselematan. Beberapa pariwisatawan pernah tenggelam, ada yang dapat diselamatkan namun ada juga yang terseret ombak dan tidak bisa diselamatkan. Oleh karenanya, dalam perancangan desain harus ditentukan area aman dan tidak aman untuk pariwisata. Wisatawan tetap boleh bermain air di tepi pantai pada area yang aman. Apabila dipertimbangkan untuk kegiatan berenang yang menarik wisatawan, dapat diletakkan pada area yang berjarak dengan membuat kolam renang tersendiri, tidak berada di pantai.

Bibir pantai dihiasi tumbuhan pohon kelapa dan beberapa tanaman lain seperti pandan laut dan rumput laut serta semak-semak liar khas pantai. Pada kondisi eksisting, ada ruang penunjang pariwisata yakni beberapa pondok kecil untuk bersantai warung makan dan souvenir. Ruang lebar juga tersedia pada pinggiran pantai untuk ruang berjalan dan berinteraksi dengan ombak. Ruang interaksi ini diidentifikasikan ada tiga kategori yakni ruang dengan ombak besar dan dikelilingi karang dengan posisi sedikit berkontur, ruang lapang dengan pemandangan yang lapang dan terdapat sebuah karang yang memecahkan ombak sehingga ombak tidak terlalu besar, dan ruang yang berada di cekungan pantai sehingga ombak relatif kecil namun ruang ini mempunyai titik pandang yang kurang luas disbanding ruang-ruang lain.

Kawasan pantai yang berpotensi menjadi obyek destinasi pariwisata alam perlu memiliki pertimbangan khusus untuk dikelola, baik dalam hal pengembangan wilayah obyek maupun penataan pesisir. Regulasi dapat menjadi koridor implementasi strategi sedangkan teori dapat menjadi dasar untuk melakukan inovasi yang diadaptasi dengan kondisi obyek. Terkait dengan upaya pengembangan potensi pantai di pesisir Kabupaten Pacitan, Pantai Klayar merupakan salah satu pantai yang sangat potensial mengingat secara infrastruktur sudah dibangun secara baik. Kemudahan akses menuju target obyek pariwisata pantai Klayar seperti pada Gambar 8, dapat berpeluang meningkatkan frekuensi kunjungan pariwisata. Tingkat kunjungan pariwisata akan semakin melaju ketika disertai dengan fasilitas penunjang paripariwisata yang menarik. 


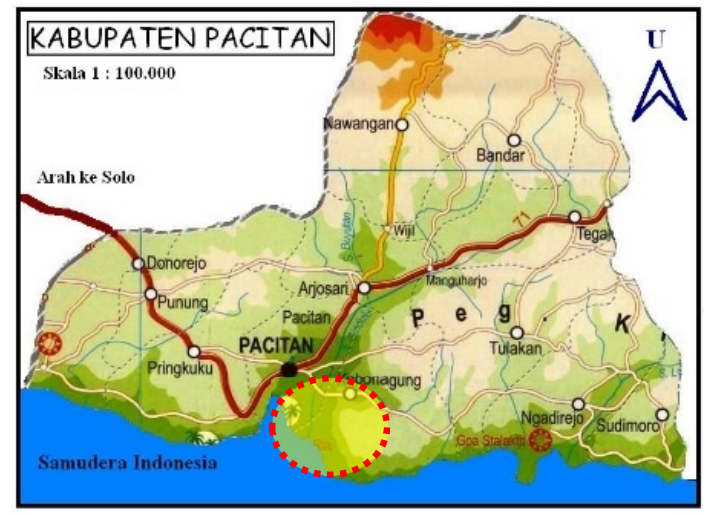

Gambar 8. Lokasi Pantai Klayar dari pusat Kota Pacitan.

Sumber: http://pacitan.do.am/

Pemetaan potensi pariwisata Kabupaten Pacitan berorientasi pada beberapa obyek alam pantai dan goa (seperti pada gambar 9), serta dengan penunjang dari sektor budaya dan kuliner. Untuk pariwisata alam pantai mencakup wilayah Pantai Klayar sebagai salah satu destinasi pariwisata yang diunggulkan. Pengelolaan pariwisata Kabupaten Pacitan secara keseluruhan meliputi dua perwilayahan yakni Destinasi Pariwisata Kabupaten (DPK); dan Kawasan Strategis Pariwisata Kabupaten (KSPK). Mekanisme pengelolaan pariwisata dikelola antara pemerintah kabupaten atau desa setempat serta pengelolaan bersama berdasarkan kategori obyek. Pantai Klayar memiliki potensi yang besar sehingga pengelolaan dilakukan secara bersama antara pemerintah kabupaten dan desa.

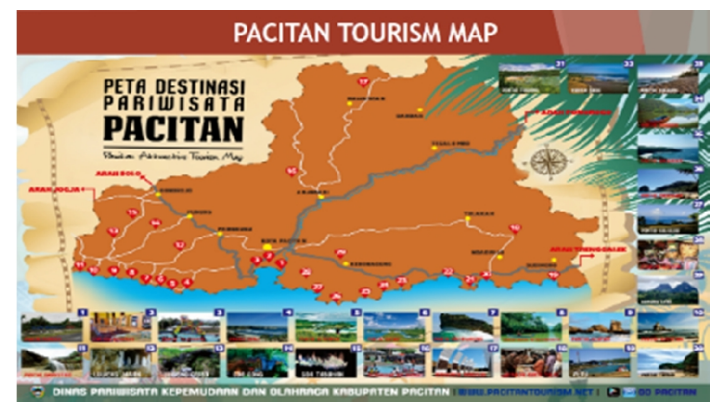

Gambar 9. Peta Pariwisata Kabupaten

Pacitan.

Sumber: (Dinas Pariwisata, 2017)

Peta pariwisata Kabupaten Pacitan menunjukkan titik-titik sebaran obyek berada di wilayah pesisir yang mayoritas menjadi destinasi pariwisata andalan Kabupaten Pacitan. Obyek pariwisata didominasi oleh pariwisata alam pantai dan karst (geopark), oleh karenanya area pesisir menjadi daerah yang sering dikunjungi pariwisatawan. Dalam infrastruktur, perlu peningkatan aksesibilitas ke obyek dengan membuat jalur penghubung antar obyek satu dengan yang lain menyambung sehingga menjadi jalur linier yang memudahkan pariwisatawan berkunjung. Strategi penataan melalui aksesiblitas jangkauan ke obyek, pantai Klayar dapat menjadi pintu gerbang masuk dari kedatangan arah barat atau gerbang keluar dari arah timur untuk menelusuri pantai-pantai sepanjang pesisir pulau Jawa bagian selatan.

Beberapa faktor yang dapat mendukung pengembangan desa pariwisata meliputi: partisipasi tokoh masyarakat yang dapat membentuk peran secara bersama-sama dalam kelompok pelaku pariwisata (Hanajayani \& Sariffuddin, 2018) dapat diimplementasikan dengan mengakomodasi partisipasi masayarakat Desa Sendang secara terpadu, membentuk komunitas pariwisata dengan kontribusi sesuai kapasitas yang dimiliki dan terus dtingkatkan. Faktor lain, teknik penataan yang mengkolaborasikan kesadaran lingkungan dan keterlibatan masyarakat memberikan dampak visual kawasan yang estetis sehingga menarik untuk dikunjungi (Titisari \& Asikin, 2015) dapat dilakukan dengan memberikan bekal ketrampilan berkarya arsitektur ekologis pada tukang-tukang lokal sehingga mempunyai ketrampilan membangun bangunan yang berciri lokal. Hubungan 
kerjasama secara terpadu dari pemangku kepentingan pariwisata (Victoria, et al., 2012) juga mampu memberikan dukungan kemajuan pembangunan desa wisata hijau yang berkelanjutan. Upaya untuk menampilkan keunikan yang bercirikhas lokal sebagai bentuk mengangkat nilai budaya dalam fasilitas penunjang pariwisata sangat perlu dipertimbangkan untuk melengkapi strategi penataan kawasan Pantai Klayar (Pramudhita, Pitana, \& Yuliani, 2016).

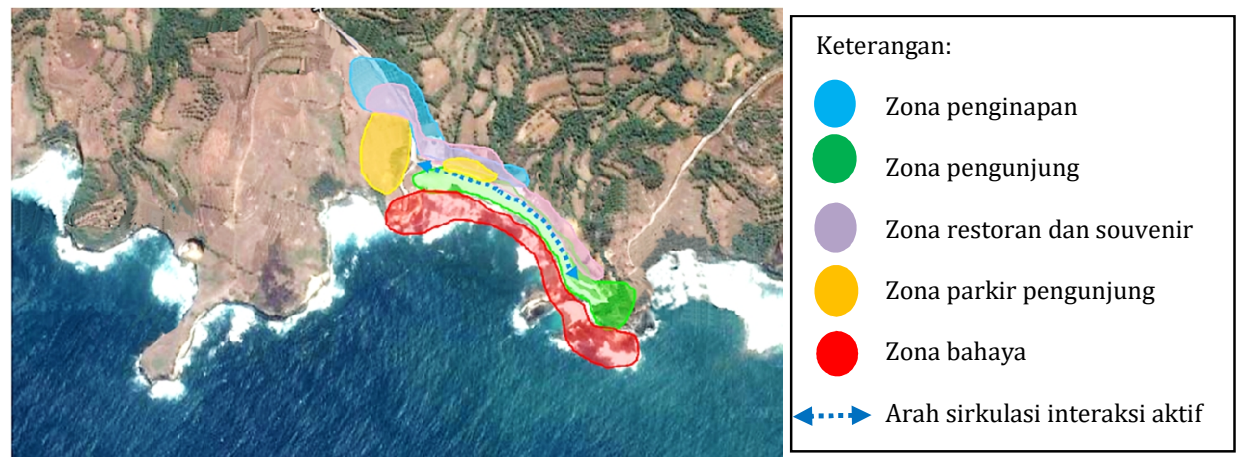

Gambar 10. Pemetaan kegiatan pariwisata di Pantai Klayar secara eksisting.

Prosedur penataan kawasan berbasis arsitektur ekologis diterapkan dengan melakukan inventarisasi dan identifikasi antara potensi yang menjadi nilai keunggulan destinasi pariwisata Pantai Klayar; memetakan kendala rawan bencana dan keselamatan pariwisata; serta menentukan panduan untuk menyusun strategi penataan kawasan berdasarkan kajian teori dan regulasi yang relevan. Pengembangan juga mempertimbangkan kebutuhan para wisatawan untuk dapat beraktifitas aktif di wilayah area wisata alam seperti yang dikemukakan oleh Prihadi dkk (D J Prihadi, 2018) Secara eksisting, hasil survei mengidentifikasikan pembagian zona kegiatan pariwisata dalam beberapa kelompok zona, yakni: zona pengunjung, zona restauran dan souvenir, zona penginapan, zona parkir dan zona bahaya seperti divisualkan pada Gambar 10. Beberapa kelompok kegiatan ada yang saling berbaur sehingga membuat kepadatan pada area tertentu. Zona-zona yang berkepadatan tinggi dapat diurai dengan penentuan kelompok kegiatan dan mengatur penataan menyesuaikan karakter kawasan.

Strategi penataan kawasan berdasarkan pemetaan rawan bencana, keselamatan pelaku pariwisata dan kelestarian keindahan alam dengan prinsip arsitektur ekologis perlu menentukan pembagian dalam beberapa kategori zona seperti pada Gambar 11, yakni: zona pariwisata terdiri zona pandang sunset, zona pandang pantai, zona interaksi; zona penunjang pariwisata; serta zona konservasi pantai.

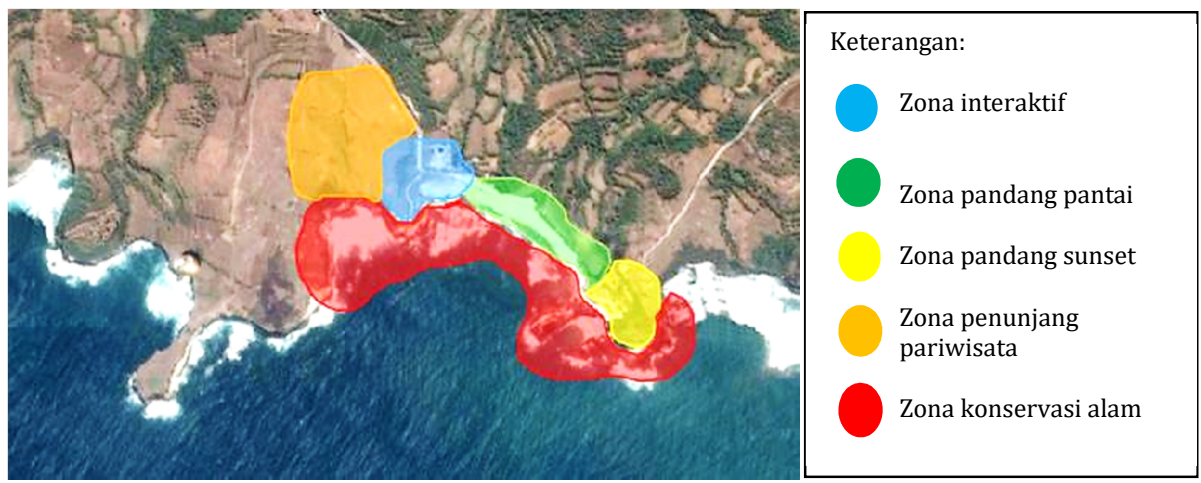

Gambar 11. Zonasi penataan kawasan Pantai Klayar.

Penataan secara mikro pada zona pariwisata melalui penentuan titik-titik atraktif dengan memberikan tanda keunikan pada lokasi kawasan meliputi: penempatan jalur 
sirkulasi, gerbang masuk dan keluar, ruang komunal, ruang restoran dan souvenir, serta ruang servis. Ruang-ruang ini membutuhkan tuntutan aksesibilitas, keamanan, kenyamanan dan ketahanan fasilitas sesuai dengan prinsip arsitektur ekologis (Frick \& Mulyani, 2006) secara detil dirangkum pada Tabel 1. Penataan ruang pariwisata alam perlu diupayakan dalam aspek kenyamanan, kebersihan dan keindahan yang alami, oleh karenanya perlu keterlibatan pengelolaan sarana dan prasarana yang menarik dan berkelanjutan. Wisatawan menghargai lingkungan alam yang sehat dan indah dan menolak destinasi tempat polusi dan perusakan lingkungan alami terjadi (UNESCO, 2009).

Tabel 1. Strategi penataan elemen mikro pada zona pariwisata.

\begin{tabular}{|c|c|c|}
\hline $\begin{array}{c}\text { Jenis ruang dan kondisi } \\
\text { eksisting }\end{array}$ & Kriteria & Strategi \\
\hline & $\begin{array}{l}\text { Bangunan visibel, aman, } \\
\text { aksesibel, menarik secara visual } \\
\text { memadukan penataan tanaman } \\
\text { lokal yang khas. }\end{array}$ & $\begin{array}{l}\text { Desain dengan ciri khas obyek } \\
\text { pesisir pantai, menggunakan bahan } \\
\text { lokal, diletakkan pada jalur } \\
\text { transportasi yang strategis dan } \\
\text { aman. }\end{array}$ \\
\hline & $\begin{array}{l}\text { Ruang sirkulasi yang aman dan } \\
\text { leluasa, aksesibel, aman dan } \\
\text { menyatu di sepanjang kawasan, } \\
\text { dengan peneduh pohon kelapa }\end{array}$ & $\begin{array}{l}\text { Menggunakan bahan material lokal } \\
\text { yang khas, perawatan elemen } \\
\text { dipertimbangkan. }\end{array}$ \\
\hline & $\begin{array}{l}\text { Rambu rawan dan mitigasi } \\
\text { bencana yang komunikatif, } \\
\text { aksesibel, mudah dijangkau, } \\
\text { petunjuk jelas, ada titik kumpul }\end{array}$ & $\begin{array}{l}\text { Tersedia papan petunjuk arah } \\
\text { dalam keadaan darurat }\end{array}$ \\
\hline & $\begin{array}{l}\text { Letak ruang yang strategis, } \\
\text { desain alami, keleluasaan } \\
\text { memandang, kenyamanan } \\
\text { menikmati, aksesibel, ruang } \\
\text { komunal bervariasi menyatu } \\
\text { dengan alam }\end{array}$ & $\begin{array}{l}\text { Desain dengan bentuk pondok } \\
\text { sederhana yang khas namun } \\
\text { memiliki kualitas yang baik, } \\
\text { misalnya menggunakan material } \\
\text { pohon kelapa. }\end{array}$ \\
\hline Ruang pandang sunset & $\begin{array}{l}\text { Ruang yang bernuansa pantai, } \\
\text { keleluasaan memandang, } \\
\text { kenyamanan menikmati, } \\
\text { aksesibel dipadu dengan tatanan } \\
\text { tanaman lokal seperti pandan } \\
\text { laut }\end{array}$ & $\begin{array}{l}\text { Desain ruang berkelompok, dibuat } \\
\text { lebih unik dengan bentuk yang khas } \\
\text { memiliki kualitas bahan yang awet, } \\
\text { misalnya menggunakan material } \\
\text { pohon kelapa, bambu. }\end{array}$ \\
\hline Ruang penunjang restoran & $\begin{array}{l}\text { Ruang duduk nyaman, desain } \\
\text { menggunakan batuan karst atau } \\
\text { batu kali ekspos akan semakin } \\
\text { memperkuat keindahan alam } \\
\text { pantai, kebersihan, ruang } \\
\text { komunal bervariasi }\end{array}$ & $\begin{array}{l}\text { Desain lebih komunal, lapang dan } \\
\text { tetap memiliki ruang pandang yang } \\
\text { leluasa ke arah pantai. }\end{array}$ \\
\hline 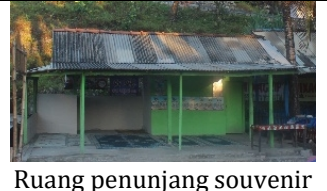 & $\begin{array}{l}\text { Ruang kios diletakkan secara } \\
\text { strategis, desain unity dinamis } \\
\text { dan alami, kebersihan, jalur } \\
\text { sirkulasi nyaman }\end{array}$ & $\begin{array}{l}\text { Letak dapat berjarak dengan area } \\
\text { pantai, dapat berdekatan dengan } \\
\text { area parkir an penunjang lain. }\end{array}$ \\
\hline
\end{tabular}




\begin{tabular}{|l|l|l|}
\hline \multicolumn{2}{|c|}{$\begin{array}{c}\text { Jenis ruang dan kondisi } \\
\text { eksisting }\end{array}$} & \multicolumn{1}{c|}{ Kriteria } \\
\hline & $\begin{array}{l}\text { Sesain unik alami dengan ekspos } \\
\text { batu karst, pertimbangan } \\
\text { kebersihan, letak strategis, } \\
\text { aksesibel }\end{array}$ & $\begin{array}{l}\text { Tampak depak tetap menarik } \\
\text { dengan paduan tanaman lokal. } \\
\text { Desain ruang minimalis untuk } \\
\text { kemudahan perawatan dan } \\
\text { kebersihan. }\end{array}$ \\
\hline $\begin{array}{c}\text { Ruang servis: kamar mandi, toilet, } \\
\text { bilas }\end{array}$ & & \\
\hline
\end{tabular}

Strategi penataan elemen mikro tersebut merupakan acuan dasar yang dapat diadaptasikan dengan potensi kawasan Pantai Klayar melalui penataan spasial secara fisik dan non fisik yaitu melibatkan masyarakat dalam pembangunan kawasan secara bergotong-royong. Inovasi dari model hubungan pemangku kepentingan pariwisata (Victoria, et al., 2012) di Pantai Klayar dapat disederhanakan dengan membagi tiga kategori pelaku pariwisata, yakni: pemerintah, masyarakat desa, dan swasata sebagai agen pariwisata. Ketiga kelompok pelaku pariwisata ini dapat berkolaborasi dalam pengelolaan, penataan spasial dan pemasaran.

\section{Kesimpulan}

Penelitian tentang kawasan Pantai Klayar di Kabupaten Pacitan menghasilkan suatu temuan tentang strategi penataan kawasan pantai sebagai destinasi pariwisata alam dengan implementasi prinsip arsitektur ekologis melalui pengelompokan zona pariwisata dan desain bangunan penunjang yang bercirikhas daerah setempat. Bangunan pariwisata di Pantai Klayar dipertimbangkan untuk menggunakan material lokal seperti kayu glugu dari pohon kelapa sebagai ciri pantai, juga bahan lokal dan alami lainnya sehingga kesan alamiah lebih menonjol. Bentukan bangunan menyesuaikan kontur yang ada, sebaiknya dihindari sistem cut-fill agar karakter tanah berkapur karst yang keras lebih diekspos. Pertimbangan rawan bencana yang menjadi kendala spesifik lokasi merupakan batasan yang penting agar terbangun penataan pariwisata yang aman dan tanggap bencana sehingga aman dan nyaman untuk dikunjungi oleh pariwisatawan. Penataan diprioritaskan pada prinsip-prinsip arsitektur ekologis yang ramah lingkungan. Prinsip arsitektur ekologis yang diterapkan untuk menentukan strategi meliputi pembagian zona pariwisata dan konservasi kawasan, penataan fitur pariwisata yang aman dan ramah lingkungan serta konservasi alam pesisir pantai untuk upaya pelestarian lingkungan secara berkelanjutan. Prinsip arsitektur ekologis pada desain ruang melalui bentuk lokal yang harmoni dengan alam, penggunaan bahan lokal dan paduan pepohonan lokal untuk menambah nilai estetika. Selain itu, prinsip arsitektur ekologis juga mengakomodasi peran aktif masyarakat pemangku kepentingan, sejalan dengan model pengembangan desa pariwisata hijau (Victoria, et al., 2012).

\section{Ucapan terimakasih}

Peneliti mengucapkan terimakasih kepada PNBP-LPPM Universitas Sebelas Maret Surakarta yang telah mendanai penelitian melalui Surat Keputusan Rektor Nomor: 259/UN27/HK/2018 tentang Penetapan Penerima Hibah Penelitian dan Pengabdian kepada Masyarakat Dana Anggaran Penerimaan Negara Bukan Pajak (PNBP) Universitas Sebelas Maret Surakarta Tahun 2018 tanggal 12 Maret 2018 dengan pelaksanaan kegiatan yang ditandatanganii dalam kontrak nomor: 543/UN27.21/PP/2018. 


\section{Referensi}

Bupati Pacitan. (2013). Peraturan Daerah Kabupaten Pacitan No 7 Tahun 2013 tentang Penyelenggaraan Kepariwisataan. Pacitan.

D J Prihadi, A. S. (2018). Marine tourism and the locations of protected turtles on Sukamade Beach, Meru Betiri National Park, East Java. ASEAN-FEN INTERNATIONAL FISHERIES SYMPOSIUM - 2017 (pp. 1-9). IOP Conf. Series: Earth and Environmental Science.

Dinas Pariwisata. (2017). Data Kunjungan Pariwisatawan Manca Negara dan Nusantara di Kabupaten Pacitan. Pacitan: Dinas Kepemudaan, Olahraga dan Pariwisata.

Frick, H., \& Mulyani, T. H. (2006). Arsitektur Ekologis. Semarang: Kanisius dan Soegijapranata Press.

Hanajayani, G., \& Sariffuddin, S. (2018). Mengatur Desa Wisata: Peran Tokoh Masyarakat Membangun Inisiatif Kolektif dalam Pengembangan Pariwisata Berbasis Komunitas. Tataloka, 195-204.

Nazir, M. (2014). Metode Penelitian. Bogor: Ghalia Indonesia.

Pramudhita, S. W., Pitana, T. S., \& Yuliani, S. (2016). Resor Klayar dengan Pendekatan Fenomenologi Arsitektur di Kawasan Wisata Pantai Klayar Pacitan. Arsitektura, 14(1), 334-312. doi:http://dx.doi.org/10.20961/arst.v14i1.12236

Riparkab. (2016). Rencana Induk Pembangunan Kepariwisataan Kabupaten Pacitan. Pacitan: Peraturan Daerah Kabupaten Pacitan Nomor 12 Tahun 2016.

Titisari, E. Y., \& Asikin, D. (2015). Penataan Lansekap pada Program Kampung Agropreneur di Tembalangan Malang. RUAS, 12-19.

UNESCO. (2009). Sustainable Tourism Development. UNESCO Regional Bureau for Science.

Victoria, Sambodo, L., Widodo, S., Hermantoro, H., Hartati, C., \& Vitriani, D. (2012). Buku Panduan Pengembangan Desa Wisata Hijau. Jakarta: Kementerian Koperasi dan UKM Republik Indonesia. 